\title{
Identification of new glutamate decarboxylases from Streptomyces for efficient production of $\gamma$-aminobutyric acid in engineered Escherichia coli
}

\author{
Haina Yuan ${ }^{1,2}$, Hongbo Wang ${ }^{1}$, Ozkan Fidan ${ }^{1}$, Yong Qin ${ }^{3}$, Gongnian Xiao ${ }^{2^{*}}$ and Jixun Zhan ${ }^{1 *}$ (D)
}

\begin{abstract}
Background: Gamma ( $($ )-Aminobutyric acid (GABA) as a bioactive compound is used extensively in functional foods, pharmaceuticals and agro-industry. It can be biosynthesized via decarboxylation of monosodium glutamate (MSG) or L-glutamic acid (L-Glu) by glutamate decarboxylase (GAD; EC4.1.1.15). GADs have been identified from a variety of microbial sources, such as Escherichia coli and lactic acid bacteria. However, no GADs from Streptomyces have been characterized. The present study is aimed to identify new GADs from Streptomyces strains and establish an efficient bioproduction platform for GABA in E. coli using these enzymes.
\end{abstract}

Results: By sequencing and analyzing the genomes of three Streptomyces strains, three putative GADs were discovered, including StGAD from Streptomyces toxytricini NRRL 15443, SsGAD from Streptomyces sp. MJ654-NF4 and ScGAD from Streptomyces chromofuscus ATCC 49982. The corresponding genes were cloned from these strains and heterologously expressed in E. coli BL21(DE3). The purified GAD proteins showed a similar molecular mass to GadB from E. coli BL21(DE3). The optimal reaction temperature is $37^{\circ} \mathrm{C}$ for all three enzymes, while the optimum $\mathrm{pH}$ values for StGAD, SsGAD and ScGAD are 5.2, 3.8 and 4.2, respectively. The kinetic parameters including $V_{\text {max }}, K_{m}, k_{c a t}$ and $k_{c a t} / K_{m}$ values were investigated and calculated through in vitro reactions. SsGAD and ScGAD showed high biocatalytic efficiency with $k_{c a t} / K_{m}$ values of 0.62 and $1.21 \mathrm{mM}^{-1} \cdot \mathrm{s}^{-1}$, respectively. In addition, engineered $E$. coli strains harboring StGAD, SsGAD and ScGAD were used as whole-cell biocatalysts for production of GABA from LGlu. E. coli/SsGAD showed the highest capability of GABA production. The cells were repeatedly used for 10 times, with an accumulated yield of $2.771 \mathrm{~kg} / \mathrm{L}$ and an average molar conversion rate of $67 \%$ within $20 \mathrm{~h}$.

Conclusions: Three new GADs have been functionally characterized from Streptomyces, among which two showed higher catalytic efficiency than previously reported GADs. Engineered E. coli harboring SsGAD provides a promising cost-effective bioconversion system for industrial production of GABA.

Keywords: Glutamate decarboxylase, Y-Aminobutyric acid, Streptomyces, Heterologous expression, Whole-cell biotransformation

\footnotetext{
* Correspondence: xiaogongnian@126.com; jixun.zhan@usu.edu

${ }^{2}$ School of Biological and Chemical Engineering, Zhejiang Provincial

Collaborative Innovation Center of Agricultural Biological Resources

Biochemical Manufacturing, Zhejiang Provincial Key Lab for Chem\&Bio

Processing Technology of Farm Produces, Zhejiang University of Science and

Technology, Hangzhou 310023, Zhejiang, China

${ }^{1}$ Department of Biological Engineering, Utah State University, 4105 Old Main

Hill, Logan, UT 84322-4105, USA

Full list of author information is available at the end of the article
}

(c) The Author(s). 2019 Open Access This article is distributed under the terms of the Creative Commons Attribution 4.0 International License (http://creativecommons.org/licenses/by/4.0/), which permits unrestricted use, distribution, and reproduction in any medium, provided you give appropriate credit to the original author(s) and the source, provide a link to the Creative Commons license, and indicate if changes were made. The Creative Commons Public Domain Dedication waiver (http://creativecommons.org/publicdomain/zero/1.0/) applies to the data made available in this article, unless otherwise stated. 


\section{Background}

Gamma ( $\gamma$ )-Aminobutyric acid (GABA), also named 4-aminobutyric acid, is a non-proteinogenic water-soluble amino acid generally existing in various animal brains, plants and bacteria [1]. GABA considered as one of inhibitory neurotransmitters has been applied extensively to functional foods, pharmaceuticals and agro-industry due to its various biological activities such as hypotensive, epilepsy treatment, asthma control, sleep and memory improvement, hormone-regulating and obesity-preventing effects [2]. 2-Pyrrolidone was reported to be applied to chemically synthesize GABA, which composed the linear polymer compound named as nylon 4, a biodegradable plastic material [3]. As illustrated in Fig. 1, GABA is biosynthesized in the cells through decarboxylation of L-glutamate catalyzed by glutamate decarboxylase (GAD; EC4.1.1.15) [4, 5].

GAD is a pyridoxal $5^{\prime}$-phosphate (PLP)-dependent intracellular enzyme widely distributed in various biogenetic resources [6]. Most reported natural GADs exhibit their higher catalytic capacity under acidic conditions, and the crystal structure of $E$. coli GAD revealed the molecular mechanism to some extent [7-9]. The optimal catalysis $\mathrm{pH}$ values of bacterial GADs were reported to be in the range from 3.8 to 4.6 [10]. Obviously, this catalytic property of GAD was adverse to the industrial scale bio-manufacture of GABA on account of the cost of desalination process. There are numerous genetically engineered microorganisms reported to possess higher activity in basic conditions and enhanced GABA yield [11]. To date, GABA was mainly synthesized from MSG or L-Glu by applying the purified GAD enzyme or whole-cell/resting-cell biocatalysts [10]. The whole-cell bioconversion exhibits obvious superiority to the catalysis with purified enzyme because of its great efficiency, relatively easy preparation and low costs. Thus, it has been widely applied in industrial scale production of valuable compounds [12]. GAD has also been used in the early diagnosis of type I diabetes. GADs have been isolated from various microbial sources for industrial purposes, such as E. coli, lactic acid bacteria (LAB), Streptococcus salivarius, Bacillus megaterium, Pyrococcus horikoshii, Aspergillus oryzae and Neurospora crassa [4].
Streptomyces is rich in natural products with various biological activities, such as antibacterial, antiviral, anti-cholesterol, antiprotozoan and antitumor properties [13]. As a result, Streptomyces is well studied for natural product discovery and biosynthesis. However, GADs from this genus have never characterized. Therefore, it is of interest to explore this untapped source for new GADs and reveal their potential in GABA production. In this work, we sequenced and analyzed the genomes of three Streptomyces species including Streptomyces toxytricini NRRL 15443, Streptomyces sp. MJ654-NF4 and Streptomyces chromofuscus ATCC 49982. Each strain was found to harbor a putative gad gene, including Stgad from S. toxytricini, Ssgad from Streptomyces sp. and Scgad from S. chromofuscus. We cloned these three gad genes from the corresponding hosts and expressed them in E. coli BL21(DE3). Recombinant StGAD, SsGAD and ScGAD were purified using Ni-NTA chromatography for enzymatic studies. These enzymes were functionally characterized as L-glutamate decarboxylase and their enzymatic properties were also investigated. SsGAD and ScGAD showed higher efficiency than previously reported GADs, with $k_{\text {cat }} / \mathrm{K}_{\mathrm{m}}$ values of 0.62 and $1.21 \mathrm{mM}^{-}$ ${ }^{1} \cdot \mathrm{s}^{-1}$, respectively. Finally, we tested the capability of engineered E. coli BL21(DE3) strains harboring StGAD, SsGAD and ScGAD for GABA production. E. coli/ SsGAD showed the best performance as whole-cell biocatalyst and gave an accumulated GABA yield of 2.771 $\mathrm{kg} / \mathrm{L}$ after repeated use for 10 times. This work provides an efficient biosynthetic platform for industrial production of GABA.

\section{Results}

Amino acid sequence analysis of three putative GADs from Streptomyces

We have sequenced the genomes of $S$. toxytricini NRRL 15443, Streptomyces sp. MJ654-NF4, and S. chromofuscus ATCC $49982[14,15]$. Analysis of these genomes revealed that each of these three Streptomyces strains contains a putative GAD gene. Based on the Latin names of the strains, these putative genes were named Stgad, Ssgad and Scgad, respectively. BLAST analysis of the amino acid sequences of these GADs indicated that they shared $53 \%$ or lower identities with previously reported<smiles>N[C](CCC(=O)O)C(=O)O</smiles>
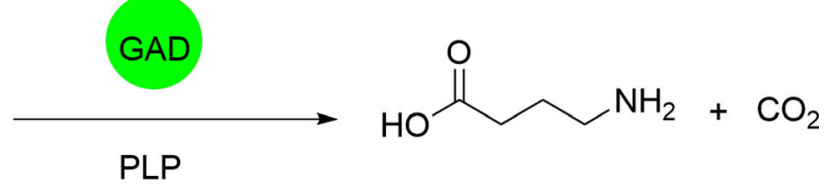

L-Glutamate

GABA

Fig. 1 GABA production from L-glutamate by glutamate decarboxylase (GAD) with pyridoxal-5'-phosphate (PLP) as a cofactor 
Table 1 Identities of StGAD, SsGAD and ScGAD with known GADs

\begin{tabular}{|c|c|c|c|c|}
\hline \multirow[t]{3}{*}{ Known GADs } & \multicolumn{3}{|c|}{ Streptomyces GADs } & \multirow[t]{3}{*}{ References } \\
\hline & StGAD & SsGAD & $\overline{S c G A D}$ & \\
\hline & \multicolumn{3}{|l|}{ Identities } & \\
\hline Escherichia coli BL21(DE3) GadB & $50 \%$ & $48 \%$ & $46 \%$ & {$[25]$} \\
\hline Escherichia coli BL21(DE3) GadA & $50 \%$ & $48 \%$ & $46 \%$ & {$[25]$} \\
\hline Bacillus cereus ATCC 10876 GAD & $52 \%$ & $52 \%$ & $53 \%$ & [24] \\
\hline Listeria monocytogenes GAD & $48 \%$ & $46 \%$ & $45 \%$ & [22] \\
\hline Lactobacillus brevis CGMCC 1306 GAD & $48 \%$ & $44 \%$ & $46 \%$ & {$[20]$} \\
\hline Lactococcus lactis subsp.cremoris MG1363 GAD & $45 \%$ & $45 \%$ & $47 \%$ & {$[23]$} \\
\hline Lactobacillus plantarum Taj-Apis362 GAD & $47 \%$ & $44 \%$ & $48 \%$ & [21] \\
\hline
\end{tabular}

GADs listed in Table 1. All these three putative GADs contain the amino acid residues GI(V/S) TY(F)D(T)G (245-250, numbering according to the sequence of ScGAD) conserved for the catalytic site of GADs [16, 17] in Additional file 1: Figure S1. The amino acid residues HV(I)DG(A) ASGG (276-283) are highly conserved in PLP-dependent decarboxylases, such as the GAD from Lactobacillus brevis CGMCC 1306 [18, 19]. In addition, the IN(S) T(V/A)SGHKYGLV(A)YPGVGW$\mathrm{V}(\mathrm{A}) \mathrm{L}(\mathrm{V} / \mathrm{I}) \mathrm{WR}$ (307-327) motif is a PLP binding domain, in which the conserved lysine residue (K313) was indicated to be an active site for binding of PLP $[16,19]$. Moreover, this lysine residue is essential for GAD decarboxylation, formation of aldimine, hydrolysis and product release. Therefore, the sequence analysis suggested that StGAD, ScGAD and SsGAD are functional GADs. A phylogenetic tree was built for the three Streptomyces GADs and several reported GADs, including Lactobacillus brevis CGMCC 1306 GAD [20], Lactobacillus plantarum Taj-Apis362 GAD [21], Listeria monocytogenes GAD [22], Lactococcus lactis subsp.cremoris MG1363 GAD [23], Bacillus cereus ATCC 10876 GAD [24], Escherichia coli BL21(DE3) GadB [25], and Escherichia coli BL21(DE3) GadA [25]. As shown in Fig. 2, all three Streptomyces GADs form their own clades that are different from those reported GADs. StGAD is in one clade, while SsGAD and ScGAD are relatively similar and were grouped into another clade.

\section{Overexpression and purification of recombinant StGAD, SsGAD, ScGAD and GadB}

In order to functionally characterize these putative GADs, we next attempted to express these enzymes in E. coli BL21(DE3). GadB is a well characterized GAD from $E$. coli and thus was used as a reference enzyme for comparison. These genes were cloned from the genome of the hosts and ligated into pET28a. The resulting plasmids, including pHW1 (pET28a-GadB), pHW4 (pET28a-StGAD), pHY1 (pET28a-ScGAD) and pHY6 (pET28a-SsGAD), were expressed in E. coli BL21(DE3). SDS-PAGE analysis (Fig. 3a) showed that all proteins (52-56 kDa) can be expressed in this strain. The calculated molecular weights were $53 \mathrm{kDa}$ for StGAD, 54.7 $\mathrm{kDa}$ for SsGAD, $56.3 \mathrm{kDa}$ for ScGAD and $52.7 \mathrm{kDa}$ for GadB. Notably, StGAD, SsGAD and GadB were expressed well at $28^{\circ} \mathrm{C}$, while more soluble ScGAD was produced in E. coli at $18{ }^{\circ} \mathrm{C}$ than $28^{\circ} \mathrm{C}$. These four $\mathrm{His}_{6}{ }^{--}$ tagged GADs were purified by Ni-NTA affinity

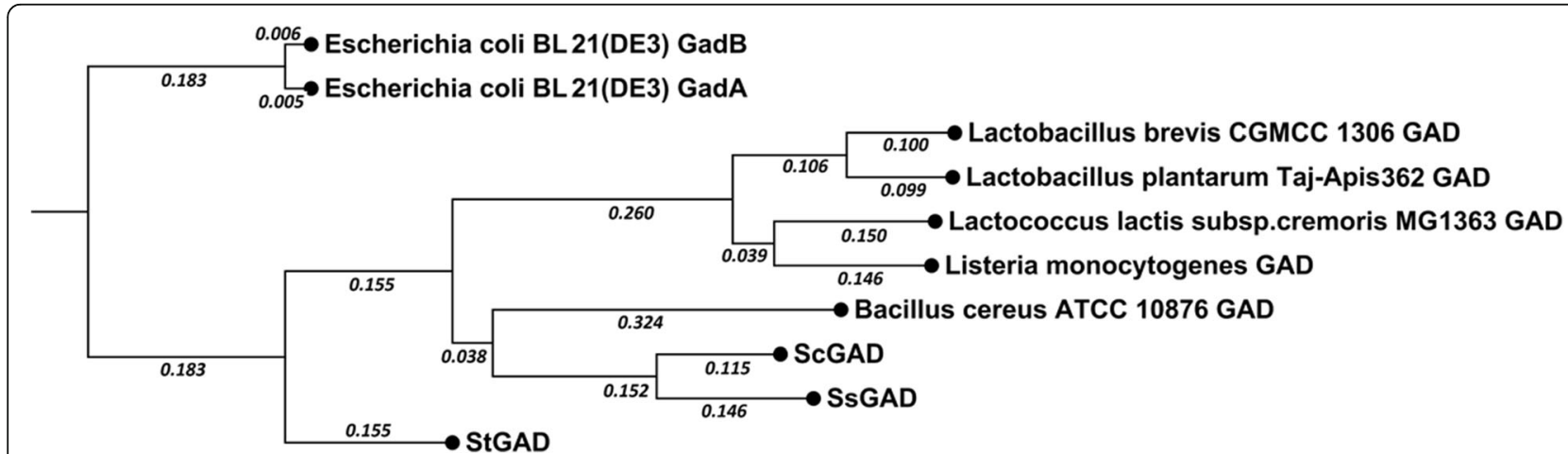

Fig. 2 Phylogenetic tree of GADs. The GAD sequences used include StGAD, ScGAD, SsGAD, Lactobacillus brevis CGMCC 1306 GAD, Lactobacillus plantarum Taj-Apis362 GAD, Listeria monocytogenes GAD, Lactococcus lactis subsp. cremoris MG1363 GAD, Bacillus cereus ATCC 10876 GAD, Escherichia coli BL21(DE3) GadB, and Escherichia coli BL21(DE3) GadA 

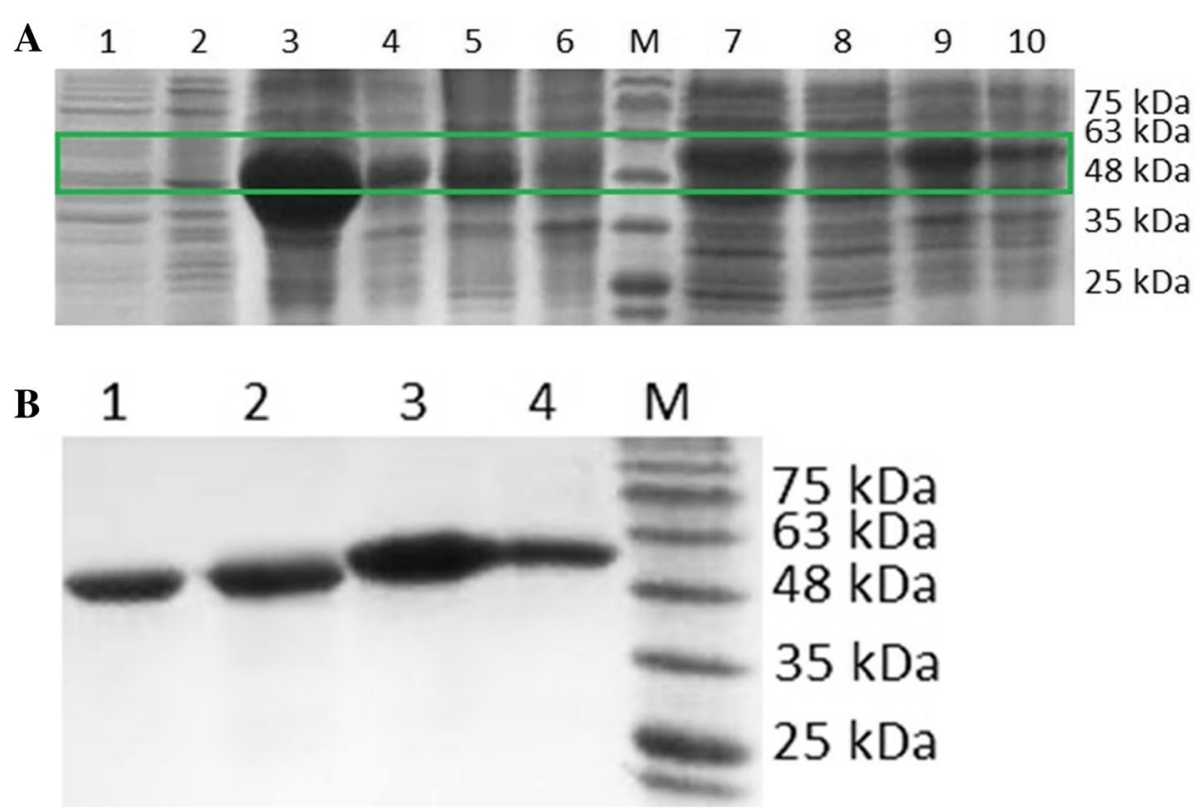

Fig. 3 SDS-PAGE analysis of expression and purification of GADs from E. coli BL21(DE3). a Expression of GadB, StGAD, ScGAD, and SsGAD in E. coli BL21(DE3). M: protein ladder; 1 and 2: insoluble and soluble fractions of E. coli BL21(DE3)/pET28a (vector control); 3 and 4: soluble and insoluble fractions of E. coli BL21(DE3)/GadB; 5 and 6: soluble and insoluble fractions of E. coli BL21(DE3)/StGAD; 7 and 8: soluble and insoluble fractions of E. coli BL21(DE3)/SSGAD; 9 and 10: soluble and insoluble fractions of E. coli BL21(DE3)/ScGAD. b GADs purified from the engineered $E$. coli BL21(DE3) strains. 1: GadB; 2: StGAD; 3: SsGAD; 4: ScGAD. StGAD, SsGAD and GadB were expressed in E. coli BL21(DE3) at $28^{\circ} \mathrm{C}$, while ScGAD was expressed at $18^{\circ} \mathrm{C}$. The target band of the GADs are in the green box

chromatography to homogeneity (Fig. 3b) for the following enzymatic studies. The isolation yields of GadB, StGAD, SsGAD and ScGAD were $60.5 \pm 2.5,33.1 \pm 1.7$, $50.0 \pm 3.2$ and $20.5 \pm 2.4 \mathrm{mg} / \mathrm{L}$, respectively.

\section{Functional identification of three Streptomyces GADs}

The purified GADs were subjected to in vitro reactions using monosodium glutamate (MSG) as the substrate, with GadB from E. coli as the positive control. All the three GADs were found to be able to convert MSG to GABA, confirming that they are indeed L-glutamate decarboxylases. GAD requires proton participation to perform the glutamate decarboxylation reaction [26]. The optimum $\mathrm{pH}$ of bacterial GADs has been reported to be in the range of 4.0-5.0 [19,27,28]. The activity of the three Streptomyces GADs were tested at $37^{\circ} \mathrm{C}$ and different $\mathrm{pH}$ values ranging from 2.6 to 6.0. The optimum activity of StGAD, SsGAD, and ScGAD was observed at pH 5.2, 3.8, and 4.2, respectively (Fig. 4a). These were different from the characterized GadB for which the optimum $\mathrm{pH}$ value is 4 [27].

We then tested the activity of StGAD, SsGAD, and ScGAD at five different reaction temperatures including $18,28,37,50$ and $60^{\circ} \mathrm{C}$. Interestingly, the optimal temperature for all three GADs were found to be $37^{\circ} \mathrm{C}$ (Fig. 4b). The three purified GADs exhibited significantly different catalytic efficiency $(p<0.05)$. ScGAD exhibited the highest conversion rate, which was 68 -fold and 1.7-fold of those of StGAD and GadB, respectively. Similarly, SsGAD showed around 60-fold and 1.5-fold stronger catalytic activity than those of StGAD and GadB.

\section{Determination of the kinetic parameters of the three Streptomyces GADs}

To understand the properties and catalytic efficiency of the three Streptomyces GADs, the $\mathrm{K}_{\mathrm{m}}, V_{\max }$ and $k_{\text {cat }}$ values of StGAD, SsGAD, ScGAD and GadB were measured using MSG as the substrate and were calculated from corresponding Lineweaver-Burk plots in Fig. 4c. The $K_{m}$ values for StGAD, SsGAD ScGAD and $\mathrm{GadB}$ were $7.67 \pm 0.55,35.17 \pm 2.12,23.25 \pm 2.07$, and $35.83 \pm 2.40 \mathrm{mM}$, respectively (Table 2), indicating that these enzymes have different affinity to MSG. The $V_{\max }$ values for StGAD, SsGAD and ScGAD were determined to be $0.226 \pm 0.01,23.42 \pm$ 1.57 and $29.94 \pm 2.16 \mu \mathrm{mol} \cdot \mathrm{min}^{-1} \cdot \mathrm{mg}^{-1}$, respectively. Among the three Streptomyces GADs, ScGAD was found to possess the highest efficiency, with a $k_{\text {cat }} /$ $K_{\mathrm{m}}$ value of $1.21 \pm 0.09 \mathrm{mM}^{-1} \cdot \mathrm{s}^{-1}$. SsGAD showed a $k_{\text {cat }} / \mathrm{K}_{\mathrm{m}}$ value of $0.62 \pm 0.04 \mathrm{mM}^{-1} \cdot \mathrm{s}^{-1}$, whereas StGAD is the least efficient, with a low $k_{\text {cat }} / \mathrm{K}_{\mathrm{m}}$ of $0.026 \pm 0.003 \mathrm{mM}^{-1} \cdot \mathrm{s}{ }^{-1} \quad$ (Table 2). The $k_{\text {cat }} / K_{\mathrm{m}}$ values of SsGAD and ScGAD are much higher than GadB, which is $0.31 \pm 0.02 \mathrm{mM}^{-1} \cdot \mathrm{s}^{-1}$. Therefore, 

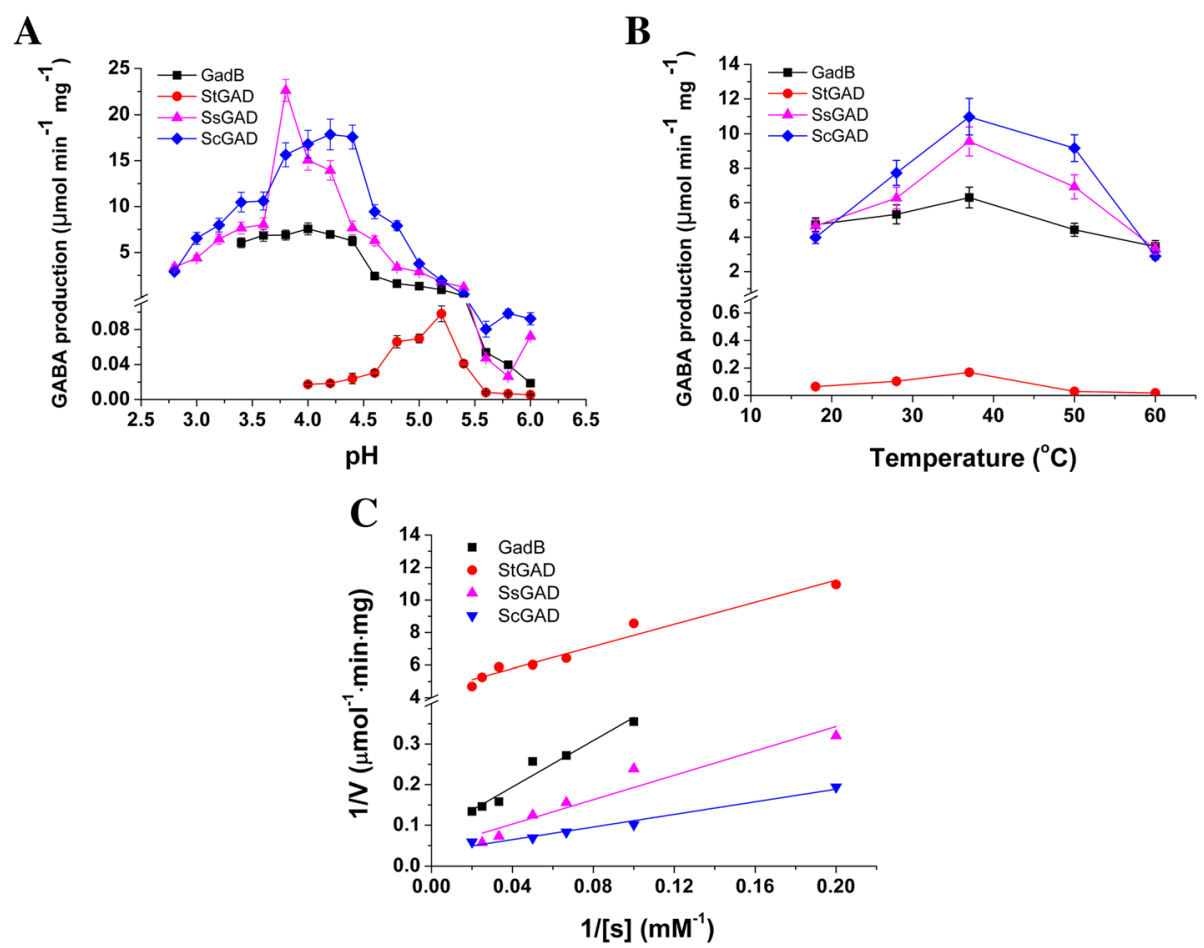

Fig. 4 Enzymatic properties of StGAD, SsGAD, ScGAD and GadB. a Effect of the reaction pH on GAD activity; $\mathbf{b}$ Effect of the reaction temperature on GAD activity; c Determination of the kinetic parameters via the Lineweaver-Burk plot

SsGAD and ScGAD are more efficient than those previously reported GADs [20, 28, 29].

\section{Bioconversion of MSG and L-Glu into GABA using engineered $E$. coli as a whole-cell biocatalyst}

MSG and L-glutamic acid (L-Glu) were respectively used as substrates to generate GABA. The engineered $E$. coli strain harboring StGAD, SsGAD or ScGAD was utilized as a whole-cell biocatalyst for GABA production. E. coli BL21(DE3)/GadB was used for comparison and wild type E. coli BL21(DE3) (WT) was used as the control. Previous studies reported that E. coli GAD showed its full activity at about $\mathrm{pH} 4-5[1,30]$. Therefore, we conducted the whole-cell biotransformation reactions in 0.1 $\mathrm{M}$ sodium acetate buffer at $\mathrm{pH}$ 4.6. We also tested the same reactions in water only. The $\mathrm{OD}_{600}$ value of the cells in the biotransformation system was 20 . Conversion of $2 \mathrm{M}$ MSG or L-Glu was conducted at $37^{\circ} \mathrm{C}$ for $1 \mathrm{~h}$. As shown in Fig. 5a, the four engineered E. coli strains had exponentially higher yields of GABA than the wild type. Among these engineering strains, E. coli BL21(DE3)/SsGAD showed the best performance, and the yields of GABA from L-Glu reached $1366 \pm 102 \mathrm{mM}$ in the sodium acetate buffer and $1319 \pm 116 \mathrm{mM}$ in water in one single-batch reaction (Fig. 5a). However, when MSG was used as the substrate, even for E. coli BL21(DE3)/SsGAD as the best catalyst, only $14.2 \pm 1.0$ $\mathrm{mM}$ and $5.9 \pm 0.3 \mathrm{mM}$ GABA was obtained in the sodium acetate buffer and in water. It was observed that L-Glu was preferred by all these GAD-harboring E. coli strains, and the yields from L-Glu were much higher than those from MSG $(p<0.05)$ in both the sodium

Table 2 Kinetic parameters for StGAD, SsGAD, ScGAD and GadB

\begin{tabular}{|c|c|c|c|c|}
\hline \multirow[t]{2}{*}{ Kinetic parameters } & \multicolumn{3}{|c|}{ Streptomyces GADs } & \multirow[t]{2}{*}{ GadB } \\
\hline & StGAD & SsGAD & ScGAD & \\
\hline$\overline{V_{\max }\left(\mu \mathrm{mol} \cdot \mathrm{min}^{-1} \cdot \mathrm{mg}^{-1}\right)}$ & $0.226 \pm 0.01^{d}$ & $23.42 \pm 1.57^{b}$ & $29.94 \pm 2.16^{\mathrm{a}}$ & $12.53 \pm 0.72^{\circ}$ \\
\hline $\mathrm{K}_{\mathrm{m}}(\mathrm{mM})$ & $7.67 \pm 0.55^{c}$ & $35.17 \pm 2.12^{a}$ & $23.25 \pm 2.07^{\mathrm{b}}$ & $35.83 \pm 2.40^{\circ}$ \\
\hline$k_{\text {cat }}\left(s^{-1}\right)$ & $0.20 \pm 0.02^{d}$ & $21.96 \pm 2.08^{b}$ & $28.08 \pm 1.99^{a}$ & $11.00 \pm 0.88^{\circ}$ \\
\hline$k_{\text {cat }} / K_{m}\left(\mathrm{mM}^{-1} \cdot \mathrm{s}^{-1}\right)$ & $0.026 \pm 0.003^{d}$ & $0.62 \pm 0.04^{b}$ & $1.21 \pm 0.09^{\mathrm{a}}$ & $0.31 \pm 0.02^{c}$ \\
\hline
\end{tabular}

Data are shown as the mean \pm standard deviation $(n=3)$. The different letters indicate significant differences among samples at a significant level of $0.05(p<$ 0.05), and the same letters indicate no significant differences 

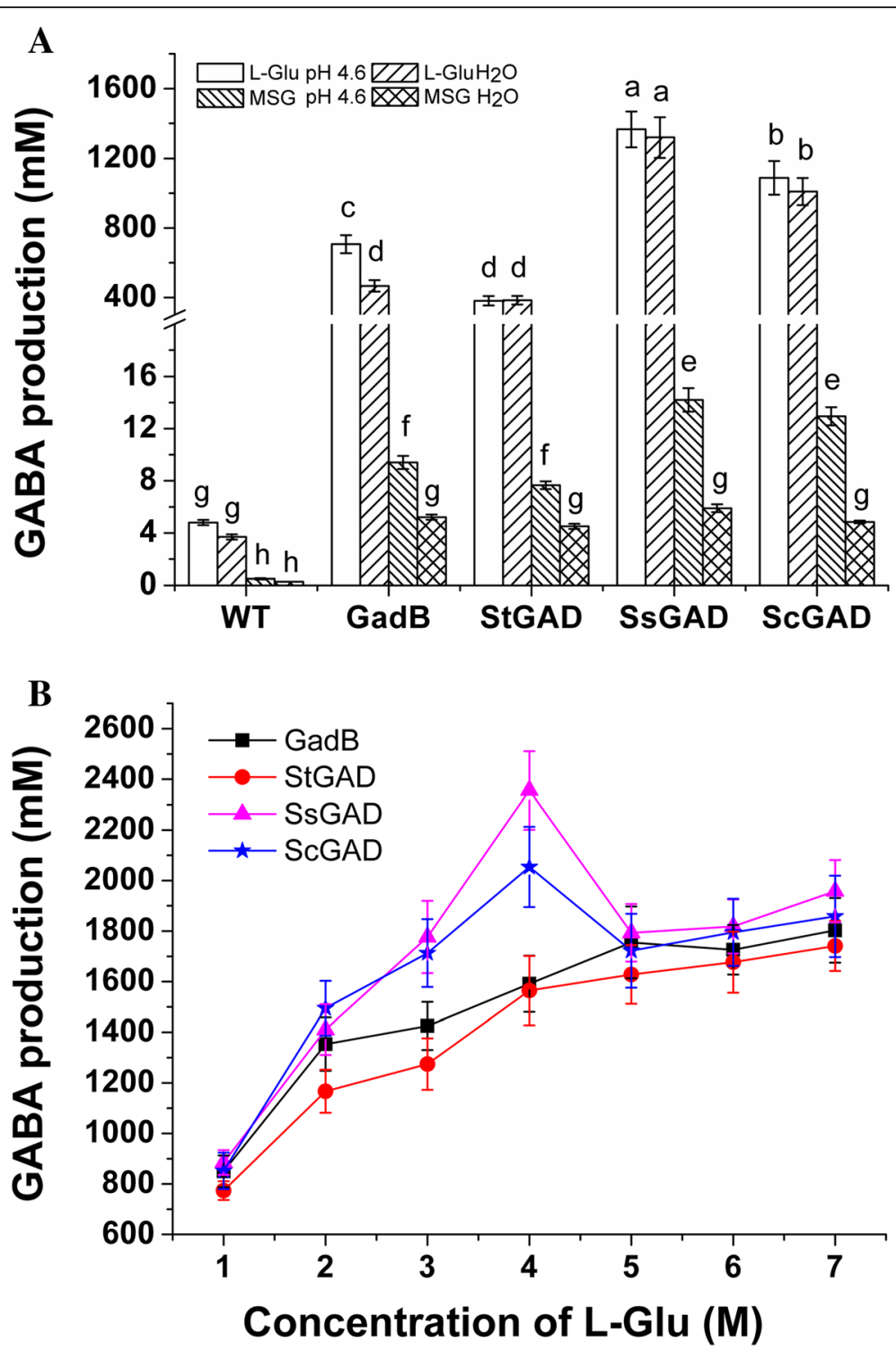

Fig. 5 GABA production by whole-cell biocatalysis with enigneered E. coli strains. (a) Bioconversion of $2 \mathrm{M}$ MSG/L-Glu to GABA in the sodium acetate buffer ( $\mathrm{pH}$ 4.6) and water; (b) Effect of L-Glu concentration on GABA production. Conversions were performed at $37^{\circ} \mathrm{C}$ for $1 \mathrm{~h}$ with a cell density of $\mathrm{OD}_{600} 20$ and PLP concentratin of $0.2 \mathrm{mM}$ in water. Data are shown as the mean \pm standard deviation $(n=3)$. The different letters indicate significant differences among samples at a significant level of $0.05(p<0.05)$, and the same letters indicate no significant differences

acetate buffer and water. For example, the yield of GABA by E. coli/SsGAD from L-Glu was 170-fold higher than that of MSG. Moreover, there was almost no significant difference between GABA production in the sodium acetate buffer and water when L-Glu was taken as the substrate (Fig. 5a). Therefore, we used L-Glu as the substrate and water as the reaction system for the following whole-cell bioconversion studies.

E. coli BL21(DE3)/StGAD, E. coli BL21(DE3)/SsGAD, E. coli $\mathrm{BL} 21(\mathrm{DE} 3) / \mathrm{ScGAD}$, and E. coli BL21(DE3)/GadB were then reacted with different concentrations of L-Glu $(1-7 \mathrm{M})$ in water. When the substrate concentration was lower than $4 \mathrm{M}$, the GABA production efficiency was high for all strains, with yields of 1.5-2.4 $\mathrm{M}$ and molar conversion rates of $77.4-88.5 \%$ within $1 \mathrm{~h}$ (Fig. 5b). However, when the L-Glu concentration was higher, the conversion efficiency decreased. When $7 \mathrm{M}$ of L-Glu was added, the conversion ratio was reduced to 24.9-28.0 mol\%. The reaction mixture system cannot be mixed well with shaking due to large amounts of insoluble L-Glu in the system, which might have impacted the reaction efficiency. Additionally, high concentrations of GABA might also inhibit the reaction. Overall, the recombinant E. coli strain harboring SsGAD exhibited a 
conversion capability superior to StGAD, ScGAD and GadB (Figs. 5a and b). Thus, this strain was chosen for the following whole-cell bioconversion studies.

\section{Effects of cell and PLP concentrations on GABA production}

The effects of cell amount and PLP concentration on GABA yield were evaluated with E. coli BL21(DE3)/ SsGAD. We first tested the reactions of this strain at different cell concentrations ranging from $\mathrm{OD}_{600} 2$ to 32, with $7 \mathrm{M} \mathrm{L}-\mathrm{Glu}$ at $37^{\circ} \mathrm{C}$ for $2 \mathrm{~h}$ (Fig. 6a). The L-Glu concentration was set the highest concentration of $7 \mathrm{M}$ to ensure that the substrate is enough for the high cell concentrations. It was found that the conversion rate increased with higher concentrations of cells. $\mathrm{OD}_{600} 20$ showed the highest conversion rate, with a yield of 3.3 M. Further increase in cell concentration did not yield more product, likely due to a too dense reaction system.

PLP is an essential cofactor for GAD-catalyzed decarboxylation of L-Glu [4]. Various concentrations of PLP were then tested with E. coli BL21(DE3)/SsGAD at $\mathrm{OD}_{600} 20$. The reactions were performed at $37^{\circ} \mathrm{C}$ for $2 \mathrm{~h}$ with $4 \mathrm{ML}-\mathrm{Glu}$. Our results showed that GABA yield reached $3335 \pm 75 \mathrm{mM}$ with the enhancement of PLP supplementation up to $0.2 \mathrm{M}$ (Fig. 6b). Further increase in the PLP concentration did not increase the production of GABA. This result agrees with those of GADs from E. coli NBRC 3806 and Lactobacillus brevis HYE1 [17, 31].

\section{GABA production of GABA from L-Glu by repeated use of} E. coli BL21(DE3)/SsGAD

We next tested whether E. coli BL21(DE3)/SsGAD can be repeatedly used for GABA production, which can reduce the production costs of GABA. The reaction time was first investigated with different concentrations of L-Glu with the cell concentration being $\mathrm{OD}_{600} 20$. When the concentration of L-Glu was $1 \mathrm{M}$, it took $2 \mathrm{~h}$ to reach $92 \mathrm{~mol} \%$ conversion. However, it took a longer time to reach the highest conversion rate for 2, 3 and $4 \mathrm{ML}$-Glu (Fig. 6c). In addition, the velocity in the first hour reached the highest for all the reactions and slowed down after $1 \mathrm{~h}$. At the first reaction hour, GABA was produced at $736 \pm 52 \mathrm{mM}(73.6 \mathrm{~mol} \%$, molar conversion ratio), $1410 \pm 101 \mathrm{mM}$ (70.5 mol\%), $1907 \pm 127 \mathrm{mM}$ (63.6 mol\%) and $2155 \pm 177 \mathrm{mM}(53.9 \mathrm{~mol} \%)$ from 1, 2, 3 and $4 \mathrm{M} \mathrm{L-Glu}$, respectively. Based on the GABA yield and productivity, $2 \mathrm{ML}$-Glu supplementation was selected for batch reactions (Fig. 6d).

For batch reactions, a cell density of $\mathrm{OD}_{600} 20$ was used. The initial concentration of L-Glu was $2 \mathrm{M}$ and
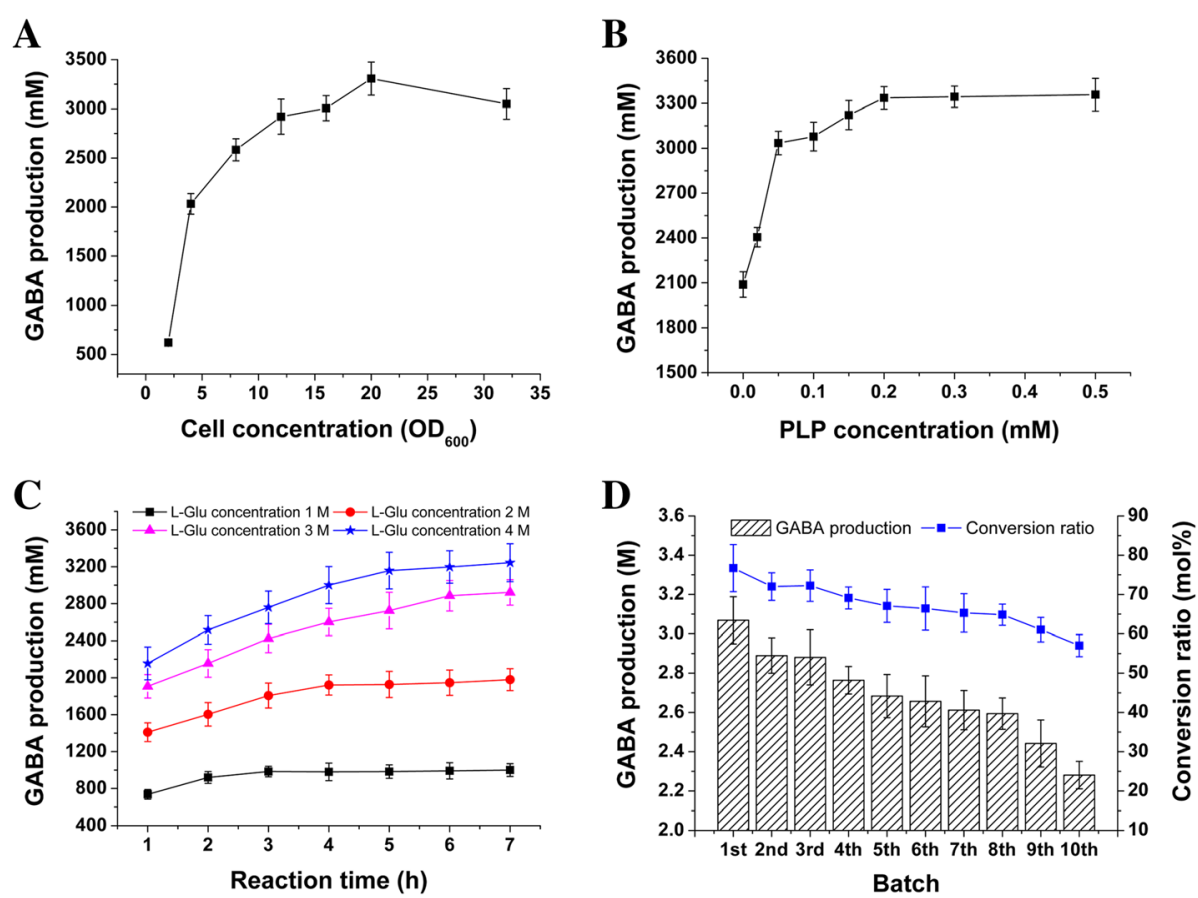

Fig. 6 Optimization of GABA production by E. coli BL21(DE3)/SsGAD from L-Glu. a Effect of the cell concentration on GABA yield. The reactions were performed with $7 \mathrm{ML}$-Glu in water at $37^{\circ} \mathrm{C}$ for $2 \mathrm{~h}$ and with a cell density of $\mathrm{OD}_{600} 20 ; \mathbf{b}$ Effect of the PLP concentration on GABA yield. The reaction was carried out at $37^{\circ} \mathrm{C}$ for $2 \mathrm{~h}$ with $4 \mathrm{M} \mathrm{L}$-Glu and a cell density of $\mathrm{OD}_{600} 20$ in water. $\mathbf{c}$ Time course analysis of GABA formation in single-batch reactions with $1 \mathrm{M}, 2 \mathrm{M}, 3 \mathrm{M}$, and $4 \mathrm{ML}$-Glu. The concentrations of cells and PLP were $\mathrm{OD}_{600} 20$ and $0.2 \mathrm{mM}$, respectively; d Batch reactions with reused $E$. coli BL21(DE3)/SsGAD with a cell density of $\mathrm{OD}_{600} 20$ 
PLP was supplemented at $0.2 \mathrm{mM}$. The bioconversion was performed at $37^{\circ} \mathrm{C}$ for $1 \mathrm{~h}$ before an additional $2 \mathrm{M}$ L-Glu was added into reaction system. The cells were then centrifuged and re-used for the next batch. We found that $E$. coli BL21(DE3)/SsGAD can be used for at least 10 batches with a conversion rate of $57-77 \mathrm{~mol} \%$ (Fig. 6d). The accumulated yield of GABA in one liter of reaction system was $26.9 \mathrm{~mol}$ (equal to $2.771 \mathrm{~kg}$ ) of GABA from a total of $40 \mathrm{~mol}$ (equal to $5.885 \mathrm{~kg}$ ) of L-Glu. This is higher than previously reported $614.15 \mathrm{~g} /$ $\mathrm{L}[1,3,4,11]$. The overall molar conversion rate and productivity were about $67 \%$ within $20 \mathrm{~h}$ and $138 \mathrm{~g} / \mathrm{L} / \mathrm{h}$, respectively. Therefore, $E$. coli BL21(DE3)/SsGAD is a promising strain for GABA production.

\section{Discussion}

GAD is a PLP-dependent decarboxylase which specifically converts L-Glu into GABA. GABA attracted large interests in its industrial promise, thus, new GADs with higher decarboxylation efficiency is primary and critical to develop cost-effective GABA biosynthetic process. Although Streptomyces strains have been well explored for physiologically active compounds, characterization of GADs from this genus has never been reported. In this work, we identified three new GADs from three different Streptomyces strains. The function and catalytic activity of StGAD, SsGAD and ScGAD were tested and confirmed with reactions using pure enzymes or cells expressing these GADs.

PLP is an essential cofactor for the efficient interactions between GAD and substrate [32]. The internal aldimine was formed to link PLP and the active-site residue K279 of L. brevis CGMCC 1306 GAD, and they catalyzed the decarboxylation reaction through the formation of this kind of Schiff base. Several other amino acid residues, including Ser126, Ser127, Ser276, Ser321, Cys66, Ile206 and His278 in L. brevis CGMCC 1306 GAD, were reported to be critical in the orientation of PLP and promotion of decarboxylation reaction [19]. Hence, PLP seems to be necessary for decarboxylation reactions of GADs in vitro. However, for whole-cell biotransformation, PLP is not required because of its natural occurrence in E. coli cells. In this work, the GABA yield was increased by $45 \%$ with 0.05 mM PLP addition compared to that of without PLP addition (Fig. 6b). When the amount of PLP was over $0.2 \mathrm{mM}$, GABA production did not increase further. In addition, PLP biosynthetic genes, $p d x S$ and $p d x T$ from Bacillus subtilis, have been reported to be successfully introduced into lysine decarboxylase-overexpressing $E$. coli strain BL-CadA without exogenous PLP requirement [33]. The crystal structure of Lactobacillus brevis CGMCC 1306 GAD indicated that a putative substrate pocket containing Lys 279, Thr 64, Thr 205, Phe 65, Phe
334, Cys 66, Gln 166, and Ser 321 and a flexible loop including residues YLGGE (308-312) played the critical role on decarboxylation of L-Glu. The amino acid residue differences among StGAD, SsGAD, and ScGAD could contribute to their significant variations on $\mathrm{K}_{\mathrm{m}}$ and $k_{\text {cat }} / \mathrm{K}_{\mathrm{m}}$ shown in Table 2 .

MSG was utilized as the substrate to determine the kinetic parameters of GadB, StGAD, SsGAD and ScGAD in the in vitro reactions because of its high water solubility $(\sim 740 \mathrm{~g} / \mathrm{L})$. In terms of GABA production with whole-cell biotransformation, reactions with MSG and L-Glu as the substrate exhibited significantly different productivity, which was attributed to GAD's acidic pH-dependent property. Microbial origin GADs could become inactive at $\mathrm{pH}$ values above 6 due to conformational changes [34]. MSG is basic in water and L-Glu is acidic. The $\mathrm{pH}$ value was gradually increased $(5.6 \pm 0.2$ / $6.88 \pm 0.1, \quad 5.9 \pm 0.1 / 6.98 \pm 0.2, \quad 6.1 \pm 0.2 / 7.09 \pm 0.1, \quad$ and $6.3 \pm 0.3 / 7.26 \pm 0.3)$ when MSG was supplemented into $0.1 \mathrm{M}$ of sodium acetate buffer ( $\mathrm{pH} 4.6) /$ water at $1 \mathrm{M}, 2$ $\mathrm{M}, 3 \mathrm{M}$ and $4 \mathrm{M}$ because of the alpha-amino group, respectively, which makes a disadvantageous $\mathrm{pH}$ environment for the catalytic activity of GADs [35]. Accordingly, MSG is not a suitable substrate for GABA production using whole cells. High concentration of MSG in the reaction system increases the $\mathrm{pH}$ and osmotic pressure, which have harmful impacts on the decarboxylation reaction and the cells, respectively. Alternatively, L-Glu is a better substrate to biosynthesize GABA on account of maintaining the acidic $\mathrm{pH}$ condition, as shown in some previous studies $[3,11,31]$. Thus, in this study, we used L-Glu as the substrate to achieve a favorable acidic $\mathrm{pH}$ environment for GABA production. L-Glu has much lower solubility in water than MSG, around $7.5 \mathrm{~g}$ per liter of water at $20^{\circ} \mathrm{C}$. As a result, the majority of L-Glu in the reaction system was in solid form and it can be continuously dissolved into water as the conversion proceeds [12]. Correspondingly, much higher yields of GABA were obtained from L-Glu than MSG (Fig. 5a), supporting that L-Glu is a better substrate for GABA production using whole cells.

The whole-cell or resting cell biocatalysis has a lot of advantages over in vitro enzymatic reactions because of the simple production process, high efficiency and low costs. Although ScGAD showed a higher $k_{\text {cat }} / \mathrm{K}_{\mathrm{m}}$ value than SsGAD (1.21 vs $0.62 \mathrm{mM}^{-1} \cdot \mathrm{s}^{-1}$ ) (Table 2), E. coli BL21(DE3)/SsGAD performed better than the strain harboring ScGAD. This is likely due to the lower expression level of ScGAD than SsGAD (20.5 vs $50 \mathrm{mg} / \mathrm{L}$ ) in E. coli. The resting cells of $E$. coli/GADs could be reused unless they are disrupted, resulting in the release of intracellular GAD out of cells and inactivation/degradation. In our work, the engineered E. coli cells with SsGAD is a 
promising candidate for an economically viable industrial scale production of GABA.

\section{Conclusions}

In conclusion, we discovered three putative GAD genes from the genomes of S. toxytricini NRRL 15443, Streptomyces sp. MJ654-NF4, and S. chromofuscus ATCC 49982. These GADs, including StGAD, SsGAD, and ScGAD, were cloned and heterologously expressed in $E$. coli BL21(DE3). The functions of these enzymes were characterized. StGAD, SsGAD, and ScGAD showed different enzymatic characteristics, and the catalytic efficiencies were different among the GADs from different Streptomyces strains. The $k_{\text {cat }} / \mathrm{K}_{\mathrm{m}}$ values of SsGAD and ScGAD are higher than previously reported GADs. An efficient whole-cell biocatalyst was developed from SsGAD to produce GABA in a cost-effective manner. In view of GABA production, engineered E. coli BL21(DE3)/SsGAD cells could be used for at least ten batches with an overall conversion rate of $67 \%$. The accumulated GABA yield reached $2.771 \mathrm{~kg}$ from $5.885 \mathrm{~kg}$ L-Glu in one liter of reaction system. Thus, this engineered strain has potential applications for industrial production of GABA as a highly efficient biocatalyst.

\section{Methods}

\section{Strains, plasmids and media}

E. coli XL1-Blue was used for general cloning purposes. E. coli BL21(DE3) was used for GAD expression and GABA production. The pJET1.2 and pET28a (+) vectors were used for cloning and expression, respectively. Phusion DNA polymerase, restriction enzymes and T4 DNA ligase were purchased from New England Biolabs. All primers were synthesized by Sigma-Aldrich. E. coli strains were routinely cultivated in Luria-Bertani (LB) medium (Fisher Scientific, USA) at $37^{\circ} \mathrm{C}$. Carbenicillin and kanamycin were used at $50 \mu \mathrm{g} / \mathrm{mL}$ as needed for selection of correct clones. All chemicals were of analytical grade and purchased from Fisher Scientific.

\section{Cloning of gad genes from Streptomyces and plasmid construction}

Three gad genes from S. toxytricini NRRL 15443 (StGAD, GenBank accession number MK303594), Streptomyces sp. MJ654-NF4 (SsGAD, GenBank accession number MK303595), S. chromofuscus ATCC 49982 (ScGAD, GenBank accession number MK303596) and gadB from E. coli BL21(DE3) (GenBank accession number ACT43333) were PCR amplified using primers listed in Table 3. The PCR reactions were performed using the following touchdown conditions: initial denaturation at $98^{\circ} \mathrm{C}$ for $5 \mathrm{~min}$, followed by 20 cycles of denaturation $\left(98^{\circ} \mathrm{C}\right.$ for $\left.30 \mathrm{~s}\right)$, annealing $\left(75^{\circ} \mathrm{C}\right.$ with $0.5^{\circ} \mathrm{C}$ decrease in each cycle for $30 \mathrm{~s})$, and elongation $\left(72^{\circ} \mathrm{C}\right.$ for $\left.2 \mathrm{~min}\right)$, then followed by 20 additional cycles of denaturation $\left(98^{\circ} \mathrm{C}\right.$ for $\left.30 \mathrm{~s}\right)$, annealing $\left(65^{\circ} \mathrm{C}\right.$ for $\left.30 \mathrm{~s}\right)$, and elongation $\left(72{ }^{\circ} \mathrm{C}\right.$ for $2 \mathrm{~min}$ ), with a final extension at $72^{\circ} \mathrm{C}$ for 10 min. The resultant 1395-bp Stgad, 1401-bp Ssgad, 1437-bp Scgad and 1401-bp gadB products were ligated into the pJET1.2 cloning vector, yielding pHW3, pHY15, pHY10 and pHW2 (Table 4). The first three plasmids were digested with NdeI and HindIII, and pHY2 that contains $\operatorname{gadB}$ was digested with NdeI and XhoI for verification. These gad genes were excised from the pJET1.2-derived plasmids and ligated into the pET28a (+) vector to yield pHW4, pHY6, pHY1 and pHW1 (Table 4), respectively. To confirm the sequences, these pET28a (+)-derived plasmids were then sent out for sequencing using the Sanger method.

\section{Expression of StGAD, SsGAD, ScGAD and GadB in E. coli BL21(DE3) and enzyme purification}

E. coli BL21(DE3) harboring pHW4, pHY6, pHY1 and pHW1 were grown at $37^{\circ} \mathrm{C}$ with shaking at $250 \mathrm{rpm}$ in $3 \mathrm{~mL}$ of LB medium containing kanamycin $(50 \mu \mathrm{g} / \mathrm{mL})$ for about $12 \mathrm{~h}$. The seed cultures were respectively transferred to $100 \mathrm{~mL}$ of LB broth containing kanamycin $(50 \mu \mathrm{g} /$ $\mathrm{mL}$ ) with shaking at $250 \mathrm{rpm}$ at $37^{\circ} \mathrm{C}$ until the $\mathrm{OD}_{600}$ value reached 0.4-0.6. Isopropyl $\beta$-D-1-thiogalactopyranoside (IPTG) was added at a final concentration of $200 \mu \mathrm{M}$ to induce GAD expression. The cultures were incubated for an

Table 3 Primers for amplifying the GAD genes from E. coli and Streptomyces

\begin{tabular}{|c|c|c|}
\hline Gene & Primers & Restriction site \\
\hline \multirow[t]{2}{*}{$\operatorname{gad} B$} & Forward: 5'-CGCCATATGGATAAGAAGCAAGTAACG-3' & Ndel \\
\hline & Reverse: 5'-CCCTCGAGTCAGGTATGTTTAAAGCTGTT-3' & Xhol \\
\hline \multirow[t]{2}{*}{ Stgad } & Forward: 5'-AACATATGGCTCTCCACAAGACGAAGGA-3' & Ndel \\
\hline & Reverse: 5'-AAAAGCTITIAGTGGTGGAAGCCGGAGCGGGGA-3' & HindllI \\
\hline \multirow[t]{2}{*}{ Ssgad } & Forward: 5'-AACATATGGCCTTGTACAAGGGCACCG-3' & Ndel \\
\hline & Reverse: 5'-AAAAGCTITIAGTGGTGGAAGCCGGCGCGGACC-3' & Hindlll \\
\hline \multirow[t]{2}{*}{ Scgad } & Forward: 5'-AACATATGCCACTCCACCAAGGCGCGGACA-3' & Ndel \\
\hline & Reverse: 5'-AAAGCTITTAGTGGTGGAAGGCGGTGGCGGCC-3' & HindIII \\
\hline
\end{tabular}


Table 4 List of plasmids used in this work

\begin{tabular}{lll}
\hline Plasmids & Description & Source \\
\hline pHW2 & gadB in pJET1.2 & This Work \\
pHW1 & gadB in pET28a & This Work \\
pHW3 & Stgad in pJET1.2 & This Work \\
pHW4 & Stgad in pET28a & This Work \\
pHY10 & Scgad in pJET1.2 & This Work \\
pHY1 & Scgad in pET28a & This Work \\
pHY15 & Ssgad in pJET1.2 & This Work \\
pHY6 & Ssgad in pET28a & This Work \\
\hline
\end{tabular}

additional $16 \mathrm{~h}$ at $28^{\circ} \mathrm{C}$ (pHW4, pHY6, pHW1) or $18^{\circ} \mathrm{C}$ (pHY1) with shaking at $250 \mathrm{rpm}$ before harvest. After centrifugation at $12,000 \times \mathrm{g}$ for $10 \mathrm{~min}$ at $4{ }^{\circ} \mathrm{C}$, the cell pellets were re-suspended in the lysis buffer $(20 \mathrm{mM}$ Tris- $\mathrm{HCl}$, $0.5 \mathrm{M} \mathrm{NaCl}, \mathrm{pH} 7.9)$ with $1 \mathrm{mM}$ dithiothreitol and disrupted by ultrasonication (Misonix Sonicator 3000, Misonix Inc., USA) on ice. The cell lysates were centrifuged at $12,000 \times \mathrm{g}$ for $10 \mathrm{~min}$. The supernatants were collected and analyzed by SDS-PAGE as soluble fractions. Cell debris were dissolved in $8 \mathrm{M}$ urea solution and analyzed on SDS-PAGE as insoluble fractions.

To purify recombinant StGAD, SsGAD, ScGAD, and $\mathrm{GadB}$, the supernatants from the cell lysates were loaded on a HisPur ${ }^{\text {Tax }} \mathrm{Ni}$-NTA affinity column (Thermo Scientific, Rockford, USA). After washing column with cold wash buffer (50 mM Tris-Hcl, 2 mM EDTA, 20 mM imidazole, $\mathrm{pH}$ 7.9), the recombinant StGAD, SsGAD, ScGAD, and GadB proteins were finally eluted with elution buffer (50 $\mathrm{mM}$ Tris-Hcl, $2 \mathrm{mM}$ EDTA, $250 \mathrm{mM}$ imidazole, $\mathrm{pH}$ 7.9). The fractions were concentrated and desalted using the $30 \mathrm{~K}$ Macrosep Advance Centrifugal Device (Pall Corporation, New York, USA). The protein concentrations were determined using the Bradford assay [36]. These enzymes were stored in $50 \%$ glycerol $(\mathrm{v} / \mathrm{v})$ at $-20^{\circ} \mathrm{C}$.

\section{Sodium dodecyl sulfate-polyacrylamide gel} electrophoresis (SDS-PAGE) analysis of protein expression SDS-PAGE was performed using 12\% separation gel, $4 \%$ stacking gel, and Laemmli's Tris-glycine electrolyte buffer system at $\mathrm{pH} 8.3$ on a discontinuous vertical slab electrophoresis system [6]. The standard marker was the BLUEstain $^{\mathrm{TM}}$ protein ladder obtained from Gold Biotechnology Inc. (St. Louis, MO, USA) with a molecular weight range of $11-245 \mathrm{kDa}$. After electrophoresis, the gel was stained with $0.1 \%$ Coomassie brilliant blue R-250 and destained with $12-15 \%$ acetic acid in water $(\mathrm{v} / \mathrm{v})$.

\section{Enzymatic activity assay and quantification of GABA formation}

The activities of StGAD, SsGAD, ScGAD and GadB were examined through in vitro reactions based on the
Berthelot method with some modifications [3, 37]. The $2.0-\mathrm{mL}$ reaction mixture consisted of $200 \mathrm{mM} \mathrm{Na}{ }_{2} \mathrm{H}$ $\mathrm{PO}_{4}$-citric acid buffer (pH5.2 for StGAD, pH 3.8 for SsGAD, pH 4.2 for ScGAD and $\mathrm{pH} 4.0$ for GadB), 50 mM L-MSG, $0.01 \mathrm{mM}$ PLP, and $50-100 \mu \mathrm{L}$ of purified enzyme. The mixtures were thoroughly mixed and incubated at $37^{\circ} \mathrm{C}$ for $30 \mathrm{~min}$ and then inactivated by boiling for $5 \mathrm{~min}$. The reaction mixtures were centrifuged, and supernatants were collected for measurement of GABA using the Berthelot reaction method. The Berthelot reaction was carried out with a total volume of $2.5 \mathrm{~mL}$ which was composed of $1.0 \mathrm{~mL}$ of reaction sample, $500 \mu \mathrm{L}$ of $\mathrm{H}_{2} \mathrm{O}, 100 \mu \mathrm{L}$ of $200 \mathrm{mM}$ sodium borate ( $\mathrm{pH} 9.0$ ), and $500 \mu \mathrm{L}$ of $6 \%$ phenol and $400 \mu \mathrm{L}$ of $5 \%(w / v)$ sodium hypochlorite. The mixtures were thoroughly mixed, boiled for $10 \mathrm{~min}$, and then immediately placed on ice bath for $20 \mathrm{~min}$. GABA concentration was calculated by measuring the absorbance at $630 \mathrm{~nm}$. 4-Aminobutyric acid (Acros Organics, New Jersey, USA) was used as standard.

\section{Investigation of reaction conditions and kinetic parameters for the recombinant GADs Optimum $\mathrm{pH}$ and temperature assay}

The effect of $\mathrm{pH}$ on the activity of the recombinant GADs was determined using $200 \mathrm{mM} \mathrm{Na} \mathrm{HPO}_{4}$-citric acid buffer at various $\mathrm{pH}$ values $(2.6-6.0)$ at $37^{\circ} \mathrm{C}$ for 30 min. The effect of temperature on GAD activity was measured by incubating the enzymes at the optimum $\mathrm{pH}$ value for $30 \mathrm{~min}$ at different temperatures $\left(18^{\circ} \mathrm{C}-\right.$ $60{ }^{\circ} \mathrm{C}$ ). Subsequently, the formation of GABA in each reaction was quantified and compared.

\section{Determination of kinetic parameters of GADs}

The kinetic parameters were estimated through in vitro reactions containing different MSG concentrations from $5 \mathrm{mM}$ to $100 \mathrm{mM}, 0.01 \mathrm{mM}$ PLP, $200 \mathrm{mM} \mathrm{Na} \mathrm{HPO}_{4}$-citric acid buffer with corresponding optimum $\mathrm{pH}$ value, and $50-100 \mu \mathrm{L}$ of purified enzyme. The $\mathrm{K}_{\mathrm{m}}$ and $V_{\max }$ values were estimated by using double reciprocal via the Lineweaver-Burk plot [17]. The $k_{\text {cat }}$ and $k_{\text {cat }} / \mathrm{K}_{\mathrm{m}}$ were then calculated.

\section{Whole-cell bioconversion process}

After induction for $16 \mathrm{~h}$ at $28^{\circ} \mathrm{C}$ or $18^{\circ} \mathrm{C}$, wild type $E$. coli BL21(DE3) and the engineered strains harboring StGAD, SsGAD, ScGAD and GadB were collected by centrifugation at $12,000 \times g$ for $20 \mathrm{~min}$ and then resuspended in the $0.1 \mathrm{M}$ sodium acetate buffer at $\mathrm{pH} 4.6$ or water with MSG or L-Glu as the substrate at appropriate concentrations. Cell density was indicated by the $\mathrm{OD}_{600}$ value. The reaction mixtures were incubated at $37^{\circ} \mathrm{C}$ for the production of GABA. 


\section{Statistical analysis}

Assays were conducted in triplicate and values were expressed as the mean \pm standard deviation. Thereafter, one-way analysis of variance and subsequent Tukey-Kramer multiple-comparison tests were conducted to evaluate the significance of differences $(p<0.05)$.

\section{Additional file}

Additional file 1: Supplementary data. (DOCX 43 kb)

\begin{abstract}
Abbreviations
GABA: Gamma(ү)-aminobutyric acid; GAD: L-glutamate decarboxylase; LAB: lactic acid bacteria; L-Glu: L-glutamate or L-glutamic acid; MSG: monosodium glutamate; SDS-PAGE: sodium dodecyl sulfatepolyacrylamide gel electrophoresis; WT: wild type
\end{abstract}

\section{Acknowledgements}

Not applicable.

\section{Funding}

This work was finically supported by the National Natural Science Foundation of China (No. 31741102), the Agricultural and Social Development Program Project (No. 171593) of Hangzhou Science and Technology Bureau of Zhejiang Province (China), the Major Science and Technology Projects and Major Agricultural Projects of Zhejiang Province (No. 2017 C02033 and No. 2018C02053) and Natural Sciences Fund of Zhejiang Province (No. LY14C200007).

\section{Availability of data and materials}

The DNA sequences of the three new GADs are available to the public in NCBI under accession numbers MK303594, MK303595, and MK303596.

\section{Authors' contributions}

JZ supervised this study. JZ and GX conceived and designed the experiments. HY, HW, OF and YQ performed the experiments. All authors analyzed the data and wrote the manuscript. All authors read and approved the final manuscript.

\section{Ethics approval and consent to participate}

Not applicable.

\section{Consent for publication}

Not applicable.

\section{Competing interests}

The authors declare that they have no competing interests.

\section{Publisher's Note}

Springer Nature remains neutral with regard to jurisdictional claims in published maps and institutional affiliations.

\section{Author details}

'Department of Biological Engineering, Utah State University, 4105 Old Main Hill, Logan, UT 84322-4105, USA. ${ }^{2}$ School of Biological and Chemical Engineering, Zhejiang Provincial Collaborative Innovation Center of Agricultural Biological Resources Biochemical Manufacturing, Zhejiang Provincial Key Lab for Chem\&Bio Processing Technology of Farm Produces, Zhejiang University of Science and Technology, Hangzhou 310023, Zhejiang, China. ${ }^{3}$ Hangzhou Viablife Biotech Co., Ltd., 1 Jingyi Road, Yuhang District, Hangzhou 311113, Zhejiang, China.
Received: 30 December 2018 Accepted: 4 March 2019

Published online: 21 March 2019

\section{References}

1. Kang TJ, Ho NAT, Pack SP. Buffer-free production of gamma-aminobutyric acid using an engineered glutamate decarboxylase from Escherichia coli. Enzym Microb Technol. 2013;53:200-5.

2. Diana M, Quílez J, Rafecas M. Gamma-aminobutyric acid as a bioactive compound in foods: a review. J Funct Foods. 2014;10:407-20.

3. Fan LQ, Li MW, Jun QY, Ming CQ, Jiang SJ, Shang YJ, Zhao LM. Increasing thermal stability of glutamate decarboxylase from Escherichia coli by sitedirected saturation mutagenesis and its application in GABA production. J Biotechnol. 2018;278:1-9.

4. Dhakal R, Bajpai VK, Baek KH. Production of GABA ( $\gamma$-aminobutyric acid) by microorganisms: a review. Brazilian J Microbiol. 2012;43:1230-41.

5. Xu N, Wei L, Liu J. Biotechnological advances and perspectives of gammaaminobutyric acid production. World J Microbiol Biotechnol. 2017:33:1-11.

6. Zhang H, Yuan YH, Chen F, Wang X. Purification and characterization of glutamate decarboxylase from rice germ. Food Chem. 2007;101:1670-6.

7. Le Vo TD, Ko JS, Park SJ, Lee SH, Hong SH. Efficient gamma-aminobutyric acid bioconversion by employing synthetic complex between glutamate decarboxylase and glutamate/GABA antiporter in engineered Escherichia coli. J Ind Microbiol Biotechnol. 2013;40:927-33.

8. Shi F, Xie Y, Jiang J, Wang N, Li Y, Wang X. Directed evolution and mutagenesis of glutamate decarboxylase from Lactobacillus brevis Lb85 to broaden the range of its activity toward a near-neutral pH. Enzym Microb Technol. 2014;61-62:35-43.

9. Choi WW, Yim SS, Lee HH, Kang JJ, Park JJ, Jeong JJ. Enhanced production of gamma-aminobutyrate (GABA) in recombinant Corynebacterium glutamicum by expressing glutamate decarboxylase active in expanded $\mathrm{pH}$ range. Microb Cell Factories. 2015;14(1):-11.

10. Lee SJ, Lee HS, Lee DW. Production of $y$-aminobutyric acid using immobilized glutamate decarboxylase from Lactobacillus plantarum. Korean J Microbiol Biotechnol. 2015;43:300-5.

11. Ke C, Yang X, Rao H, Zeng W, Hu M, Tao Y, Huang J. Whole-cell conversion of L-glutamic acid into gamma-aminobutyric acid by metabolically engineered Escherichia coli. Springerplus. 2016:5:591-8.

12. Schüürmann J, Quehl P, Festel G, Jose J. Bacterial whole-cell biocatalysts by surface display of enzymes: toward industrial application. Appl Microbiol Biotechnol. 2014;98:8031-46.

13. Rashad FM, Fathy HM, El-Zayat AS, Elghonaimy AM. Isolation and characterization of multifunctional Streptomyces species with antimicrobial, nematicidal and phytohormone activities from marine environments in Egypt. Microbiol Res. 2015;175:34-47.

14. Zeng J, Decker R, Zhan J. Biochemical characterization of a type III polyketide biosynthetic gene cluster from Streptomyces toxytricini. Appl Biochem Biotechnol. 2012;166:1020-33.

15. Shao L, Zi J, Zeng J, Zhan J. Identification of the herboxidiene biosynthetic gene cluster in Streptomyces chromofuscus ATCC 49982. Appl Environ Microbiol. 2012;78(6):2034-8.

16. Kim HW, Kashima Y, Ishikawa K, Yamano N. Purification and characterization of the first archaeal glutamate decarboxylase from Pyrococcus horikoshii. Biosci Biotechnol Biochem. 2009;73:224-7.

17. Lim HS, Seo DH, Cha IT, Lee H, Do NY, Seo MJ. Expression and characterization of glutamate decarboxylase from Lactobacillus brevis HYE1 isolated from kimchi. World J Microbiol Biotechnol. 2018:34:1-10.

18. Kim SH, Shin BH, Kim YH, Nam SW, Jeon SJ. Cloning and expression of a full-length glutamate decarboxylase gene from Lactobacillus brevis $\mathrm{BH} 2$. Biotechnol Bioprocess Eng. 2007;12:707-12.

19. Huang J, Fang H, Gai ZC, Mei JQ, Li JN, Hu S, Lv CJ, Zhao WR, Mei LH. Lactobacillus brevis CGMCC 1306 glutamate decarboxylase: crystal structure and functional analysis. Biochem Biophys Res Commun. 2018:503:1703-9.

20. Huang J, Mei L, Sheng Q, Yao S, Lin D. Purification and characterization of glutamate decarboxylase of Lactobacillus brevis CGMCC 1306 isolated from fresh milk. Chin J Chem Eng. 2007;15:157-61.

21. Tajabadi N, Baradaran A, Ebranhimpour A, Rahim RA, Bakar FA, Manap MYA, Mohammed AS, Saari N. Overexpression and optimization of glutamate decarboxylase in Lactobacillus plantarum Taj-Apis362 for high gamma-aminobutyric acid production. Microb Biotechnol. 2015;8: 623-32. 
22. Information F. Draft genome sequences of Listeria monocytogenes serotype 4b strains 944 and 2993 and serotype 1/2c strains 198 and 2932. Genome announc. 2016;4:4-5.

23. Wegmann U, Connell-motherway MO, Zomer A, Buist G, Shearman C, Canchaya C, Ventura M, Goesmann A, Gasson MJ, Kuipers OP, van Sinderen D, Kok J. Complete genome sequence of the prototype lactic acid bacterium Lactococcus lactis subsp. cremoris MG1363. J Bacteriol. 2007;189: 3256-70.

24. Ash C, Jae F, Wallbanks S, Phylogenetic C. Twenty whole-genome. Genome announc. 2014;2:4-5.

25. Jeong H, Barbe V, Lee CH, Vallenet D, Yu DS, Choi SH, Couloux A, Lee SW, Yoon SH, Cattolico L, Hur CG, Park HS, Ségurens B, Kim SC, Oh TK, Lenski RE, Studier FW, Daegelen P, Kim JF. Genome sequences of Escherichia coli B strains. J Mol Biol. 2009;394:644-52.

26. de Biase D, Pennacchietti E. Glutamate decarboxylase-dependent acid resistance in orally acquired bacteria: function, distribution and biomedical implications of the gadBC operon. Mol Microbiol. 2012;86:770-86.

27. Ueno Y, Hayakawa K, Takahashi S, Oda K. Purification and characterization of glutamate decarboxylase from Lactobadllus bvevis IFO 12005. Biosci Biotechnol Biochem. 1997;61:1168-71.

28. Komatsuzaki N, Nakamura T, Kimura T, Shima J. Characterization of glutamate decarboxylase from a high $\gamma$-aminobutyric acid (GABA)-producer, Lactobacillus paracasei. Biosci Biotechnol Biochem. 2008;72:278-85.

29. de Biase D, Tramonti A, John RA, Bossa F. Isolation, overexpression, and biochemical characterization of the two isoforms of glutamic acid decarboxylase from Escherichia coli. Protein Expres Purif. 1996:438:430-8.

30. Company MJ, Academy R. Preparation of $\psi$-aminobutyric acid using E. coli cells with high activity of glutamate decarboxylase. Appl Biochem Biotechnol. 2000;88:257-65.

31. Yamano N, Kawasaki N, Takeda S, Nakayama A. Production of 2-pyrrolidone from biobased glutamate by using Escherichia coli. J Polym Environ. 2013;21: 528-33.

32. Ueno $\mathrm{H}$. Enzymatic and structural aspects on glutamate decarboxylase. Mol Catal - B Enzym. 2000;10:67-79

33. Ma W, Cao W, Zhang B, Chen K, Liu Q, Li Y, Ouyang P. Engineering a pyridoxal 5 '-phosphate supply for cadaverine production by using Escherichia coli whole-cell biocatalysis. Sci Rep. 2015;5:15630.

34. Dinh TH, Ho NAT, Kang TJ, Mcdonald KA, Won K. Salt-free production of $Y$ aminobutyric acid from glutamate using glutamate decarboxylase separated from Escherichia coli. J Chem Technol Biotechnol. 2014;89:1432-6.

35. Lund P, Tramonti A, De Biase D. Coping with low pH: molecular strategies in neutralophilic bacteria. FEMS Microbiol Rev. 2014;38:1091-125.

36. Bradford MM. A rapid and sensitive method for the quantitation of microgram quantities of protein utilizing the principle of protein-dye binding. Anal Biochem. 1976;72:248-54

37. Wang H, Huang J, Sun L, Xu F, Zhang W, Zhan J. An efficient process for coproduction of $\gamma$-aminobutyric acid and probiotic Bacillus subtilis cells. Food Sci Biotechnol. 2019:28:155-63.

Ready to submit your research? Choose BMC and benefit from:

- fast, convenient online submission

- thorough peer review by experienced researchers in your field

- rapid publication on acceptance

- support for research data, including large and complex data types

- gold Open Access which fosters wider collaboration and increased citations

- maximum visibility for your research: over $100 \mathrm{M}$ website views per year

At $\mathrm{BMC}$, research is always in progress.

Learn more biomedcentral.com/submissions 